\title{
Between- and Within-Domain Relations of Students' Academic Emotions
}

\author{
Thomas Goetz, Anne C. Frenzel, and \\ Reinhard Pekrun \\ University of Munich
}

\author{
Nathan C. Hall \\ University of California, Irvine
}

Oliver Lüdtke

Max Planck Institute for Human Development

\begin{abstract}
The authors investigated between- and within-domain relations of academic emotions, including students' enjoyment, pride, anxiety, anger, and boredom experienced in mathematics, physics, German, and English classes $(N=542$; Grades 8 and 11). Corroborating assumptions of domain specificity, the between-domains relations of these emotions were weak and inconsistent. However, there was more domain specificity of academic emotions in Grade 11 students compared with Grade 8 students, suggesting that between-domains differentiation increased as a function of grade level. Concerning within-domain relations, emotional experiences of enjoyment and pride, anxiety, and anger and boredom were clearly differentiated. The strength of within-domain relations of academic emotions differed considerably across the 4 academic domains. However, for each of the 4 domains, within-domain relations were similar for the 2 grade levels. Methodological and educational implications as well as directions for future research are discussed.
\end{abstract}

Keywords: academic emotions, domain specificity, achievement
If a student experiences little anxiety and enjoyment yet high levels of boredom in mathematics class, is it possible to infer the intensity of anxiety, enjoyment, and boredom he or she experiences in English class? Are such cross-domain assumptions more plausible for emotions that are presumed to be more habitual in nature, such as anxiety (Zeidner, 1998), and less so for more situated emotions, such as enjoyment? Do these assumptions more accurately reflect the emotional experiences of younger or older students? In an attempt to address these questions, the first objective of the present study was to investigate between-domains relations of students' academic emotions. In particular, we studied how strongly emotions experienced in a specific domain (e.g., enjoyment in mathematics) related to the same emotional experiences in other domains (e.g., enjoyment in English) and whether there was a notable difference in the strength of between-domains relations as a function of emotion type and students' age.

In addition to issues involving between-domains relations, other questions concerning the relations among academic emotions also warrant consideration. For example, is it possible to infer from a student's level of anxiety in mathematics his or her level of enjoyment in this domain? Would such an inference be more valid in another academic domain-for example, in English classes? Are such conclusions within specific domains more applicable to the

Thomas Goetz, Anne C. Frenzel, and Reinhard Pekrun, Department of Psychology, University of Munich, Munich, Germany; Nathan C. Hall, Department of Psychology and Social Behavior, University of California, Irvine; Oliver Lüdtke, Max Planck Institute for Human Development, Berlin, Germany.

Correspondence concerning this article should be addressed to Thomas Goetz, Department of Psychology, University of Munich, Leopoldstrasse 13, D-80802, Munich, Germany. E-mail: goetz@edupsy.uni-muenchen.de emotional experiences of younger or older students? In response to these research questions, the second objective of the present study was to investigate the within-domain relations of students' academic emotions. That is, we aimed to examine the interrelations among emotional experiences not only across but also within academic domains. We were interested in the strength of withindomain relations and whether there was a notable difference in the strength of these relations as a function of subject domain and age.

\section{Between-Domains Relations of Academic Emotions}

In contrast to other psychosocial constructs, between-domains relations of academic emotions have rarely been explicitly addressed. However, a number of other psychosocial constructs show weak between-domains relations-that is, they are, to a great extent, organized along domain-specific lines. In particular, weak between-domains relations have been found for self-efficacy expectancies, causal attributions, academic self-concepts, task values, and achievement goals (e.g., Abu-Hilal \& Bahri, 2000; Bong, 2001; Bong \& Skaalvik, 2003; Marsh, 1984, 1986, 1993; Marsh \& Yeung, 1996; Möller \& Köller, 2001; Stevenson \& Newman, 1986).

The domain specificity of these constructs implies that students' emotional experiences may also be organized in domain-specific ways. Following appraisal theories of emotions, one can reasonably assume that the appraisals implied by expectancies, attributions, self-concepts, subjective values, and goals are of primary importance for the arousal of emotions (Roseman, 2001; Roseman \& Smith, 2001; Scherer, 2001; Weiner, 1985). Therefore, the situational specificity of these appraisals implies that resulting emotions, including those experienced by students in an academic context, should show situational specificity as well. 
In line with considerations derived from appraisal theories more generally, the domain specificity of students' emotions related to learning and achievement follows from the assumptions of Pekrun's $(2000,2006)$ control-value theory of achievement emotions. This theory implies that two types of appraisals are of specific relevance for the arousal of academic emotions: appraisals of control over achievement activities and their outcomes, and appraisals of the value of these activities and outcomes. Achievement-related expectancies (including self-efficacy and outcome expectancies; Pekrun, 1992), causal attributions for achievement outcomes (Weiner, 1985), and self-concepts of ability are seen as control-related cognitions, and subjective values as well as achievement goals are seen as implying value appraisals.

As such, any emotion related to academic achievement can be understood as a joint product of control and value appraisals, including students' enjoyment, pride, anxiety, anger, and boredom, as investigated in the present study. For example, enjoyment of learning is assumed to be enhanced if learning is seen as being both controllable and valuable, and greater failure-related anxiety is experienced if poor performance is appraised as relevant and not sufficiently controllable (for more on assumptions for discrete academic emotions, see Pekrun, 2006; Pekrun, Elliot, \& Maier, 2006). Therefore, to the extent that both control- and value-related constructs are organized in domain-specific ways, one of the corollaries of the control-value theory is that academic emotions should also show weak between-domains relations.

Although little empirical research has explicitly dealt with between-domains relations of academic emotions, findings from emotion research on related issues are consistent with this assumption. Marsh (1988) analyzed data from the High School and Beyond Study (National Center for Education Statistics, 1986; Grade 10) and found a negligible disattenuated correlation of .04 between anxiety in mathematics and English lessons. Marsh and Yeung (1996) analyzed data from the National Educational Longitudinal Survey of 1988 (Grade 8) and observed that affect in school-aged children was largely organized in a domain-specific way. In their study, affect was operationalized as looking forward to class, perceived usefulness of the domain, and anxiety related to asking questions in class (single-item measures), and the domains investigated were mathematics, science, social studies, and English. The strongest between-domains relationships were found between similar domains - that is, areas with related content (e.g., mathematics and science). Moreover, the affective states under investigation showed weaker between-domains relations than the respective performances in those domains (with grades as well as standardized test scores).

In a meta-analysis of 51 studies using the Mathematics Anxiety Rating Scale (Richardson \& Suinn, 1972), Hembree (1990) reported a mean correlation of -.06 between mathematics anxiety and verbal performance as well as a correlation of -.34 between the Mathematics Anxiety Rating Scale scores and mathematical performance. This finding suggests weak between-domains relations for anxiety such that if anxiety did show strong betweendomains relations, higher math anxiety would correspond with more anxiety in verbal domains, which, in turn, would translate into significantly poorer verbal performance than evidenced by the nonsignificant correlation mentioned above.

In a recent preliminary investigation by Pekrun, Goetz, Titz, and Perry (2002b), between-domains correlations in middle school students were found to be nonsignificant and near zero for academic enjoyment in mathematics, languages (German and English), music, and sports. Low between-domains correlations were observed for academic anxiety. As a follow-up to the Pekrun et al. study, a second study by Goetz, Pekrun, Hall, and Haag (2006) analyzed the interrelationships among students' emotional experiences (i.e., enjoyment, anxiety, and boredom; single-item measures) in six subject domains (Grades 7 to $10 ; N=200$ ). Again, it was found that academic emotions showed generally weak between-domains relations.

In sum, the available evidence suggests weak between-domains relations for students' emotions. However, a serious weakness of existing studies is that most used single-item measures to assess academic emotions, which raises questions about scale reliability and, consequently, the validity of results. Furthermore, previous studies did not allow for an examination of differences in the between-domains relations of academic emotions for students at different grade levels — both of which are important considerations in the present study.

\section{Between-Domains Relations as a Function of Emotion Type}

Beyond initial findings, we lack cumulative evidence on the variability of between-domains associations across different academic emotions. In other words, we lack knowledge as to whether, for example, the relations between enjoyment in mathematics and English differ from the relations between anxiety in mathematics and English. Findings of the study by Goetz et al. (2006) suggest that different academic emotions differ in their strength of between-domains relations. That is, although this study found some degree of generality across domains for anxiety, there were very weak between-domains relations for enjoyment and boredom. In a similar vein, a study by Bong (2001) showed that the strength of between-domains relations of various motivational constructs (i.e., self-efficacy, task value, and achievement goals) also differed significantly.

\section{Between-Domains Relations as a Function of Grade Level}

Our review of the existing literature revealed no research addressing age-related differences in between-domains relations of academic emotions. However, empirical evidence from motivation research suggests that motivational constructs are more differentiated in older than in younger students (see Bong, 2001, for motivational constructs in Korean middle vs. high school students, Grades 7 to 11 , an age range similar to that in the present study). In addition, theory and research on students' interest indicate that "universal interests" observable in early childhood become increasingly specific from childhood to adolescence (see Krapp, 2002).

Empirical evidence from self-concept research also indicates that the multidimensionality of this construct increases with age (see Shavelson, Hubner, \& Stanton, 1976, for the first formulation of this assumption). This assumption was recently refined by Marsh and Ayotte (2003) with respect to the differential distinctiveness hypothesis. These authors assumed that a substantial decline in correlations among theoretically distinct self-concept factors should be observed with increasing age, whereas they 
expected a much smaller or no decline in correlations among more similar factors. In their study, Marsh and Ayotte (2003) found strong support for their hypothesis in students from Grades 2 to 6 (mean ages $=7.2$ and 11.1 years, respectively). If the differential distinctiveness hypothesis is also valid for emotional experiences, between-domains relations of academic emotions should decrease with age for emotional experiences in disparate domains (e.g., mathematics and English). There should also be less or no decrease in between-domains relations for emotions experienced in related subject areas (e.g., mathematics and science). Nevertheless, empirical evidence in support of this assumption is lacking.

\section{Within-Domain Relations of Academic Emotions}

There are numerous theoretical models that address the interrelations of distinct emotions, primarily in terms of underlying dimensions such as activation, valence, intensity, and duration (e.g., Ricci-Bitti \& Scherer, 1986; Shaver, Schwartz, Kirson, \& O'Connor, 1987; Wallbott \& Scherer, 1988). An obvious and ubiquitous dimension is the valence of emotional experiences, which refers to positive versus negative affect (often also labeled pleasant vs. unpleasant affect; Larsen \& Diener, 1992). A second, frequently used dimension is activation, which refers to the extent to which a given emotion implies affective arousal.

Watson and Tellegen's (1985) circumplex model represents an approach that takes both valence and activation into account (for an application to academic emotions, see Pekrun, Goetz, Titz, \& Perry, 2002a; see also Goetz, Zirngibl, Pekrun, \& Hall, 2003). According to this model, four groups of emotional experiences can be differentiated (cf. Larsen \& Diener, 1992): (a) emotions that are positive and activating (e.g., enjoyment, pride, hope), (b) emotions that are positive and deactivating (e.g., relief, relaxation), (c) emotions that are negative and activating (e.g., anxiety, anger, shame, guilt), and (d) emotions that are negative and deactivating (e.g., boredom, hopelessness, disappointment). However, despite the relevance of this circumplex model for understanding academic emotions, this and other dimensional models do not account for differences based on specific academic domains. In fact, only a few empirical studies have analyzed relations between different emotions in a specific academic domain. In two mathematicsrelated studies (Kleine, Goetz, Pekrun, \& Hall, 2005, Grade 5; Goetz, 2004, Grades 5 and 10), we found support for a categorization of academic emotions along the two dimensions of valence and activation. Nonetheless, research comparing the pattern of within-domain relations for academic emotions across different academic domains is lacking.

\section{Within-Domain Relations as a Function of Academic Domain}

In the research literature on academic emotions, we could not find any theoretical approach or empirical studies addressing domain-related differences in the interconnectedness of emotional experiences within domains. As a consequence, we do not know, for example, whether the relations between enjoyment and anxiety in mathematics differ from the relations between these emotions in English. However, some results from motivation research have shown that the pattern of interrelations for motivational constructs is relatively stable across different domains (see Bong, 2001, for relationships among self-efficacy, task value, and achievement goals in the domains of mathematics, science, and languages). Whether these results translate to emotion constructs remains to be seen.

\section{Within-Domain Relations as a Function of Grade Level}

Concerning differences of within-domain relations in academic emotions for students at different grade levels, empirical research is also lacking. For example, we do not know whether the relations between enjoyment and anxiety in mathematics differ between younger and older students. Although some empirical evidence from motivation research suggests that within-domain associations for academic motivation are relatively stable across different grade levels (Bong, 2001, for results in Korean middle vs. high school students, Grades 7 to 11), the extent to which these findings generalize to the study of academic emotions is unclear.

\section{Research Hypotheses}

The present study examined three hypotheses related to between-domains relations of academic emotions (Hypotheses 1a, $1 \mathrm{~b}$, and 1c) and three hypotheses related to within-domain relations of academic emotions (Hypotheses 2a, 2b, and 2c). In choosing which emotions to assess, we used two selection criteria. First, we wanted to assess emotions that were conceptually distinct. As such, we based our selection of emotions on the above-mentioned dimensions of activation and valence (Watson \& Tellegen, 1985).

Second, we searched the research literature for emotions that are particularly salient in academic settings (see Goetz, 2004; Pekrun et al., 2002a). As a result of these two criteria, we chose to assess the following five emotions: enjoyment and pride (positive and activating), anxiety and anger (negative and activating), and boredom (negative and deactivating). We did not examine positive deactivating emotions (e.g., relief, relaxation) because they have rarely been included in studies on academic emotions and have not been considered to be as relevant as emotions from the other three categories in the extant research literature (Pekrun et al., 2002b; Weiner, 1985). In addition, these emotions are more often experienced following an academic achievement situation rather than during such situations, which is the focus of this study. With respect to the academic domains in which each of the five emotions was assessed, we focused on four major school subjects taught to all students in our study - namely, mathematics, physics, German, and English.

\section{Between-Domains Relations of Academic Emotions}

Hypothesis 1a-Strength of between-domains relations. Based on the findings of previous research, we expected that the correlations of enjoyment, pride, anxiety, anger, and boredom across the subject domains of mathematics, physics, German, and English would be rather weak. However, we assumed that betweendomains relations of emotional experiences would be stronger between similar domains (e.g., mathematics, physics) than across dissimilar domains.

To investigate the convergent and divergent validity of the domain-specific emotion constructs, we included achievement outcomes (grades) in our analysis on between-domains relations. We 
hypothesized that we would find the strongest relationships between achievement and emotional experiences in the same domain (supporting the convergent validity of emotion measures), substantial relations between emotional experiences and achievement in similar domains, and small correlations between these variables in dissimilar domains (supporting the divergent validity of the emotions measures).

Hypothesis $1 b$-Between-domains relations as a function of emotion type. On the basis of findings of our previous research (Goetz et al., 2006), we hypothesized that enjoyment would show weaker between-domains relations than boredom and anxiety. As there is a lack of research on between-domains relations for pride and anger, the current study is exploratory in nature with respect to the strength of between-domains relations for these specific academic emotions.

Hypothesis 1c-Between-domains relations as a function of grade level. As outlined above, research on motivation, interest, and self-concept indicates that their between-domains relations are stronger in younger than in older students. It is assumed that this premise is also valid for emotional experiences. Referring to Marsh and Ayotte's (2003) differential distinctiveness hypothesis, we also hypothesized that grade-related differences in the strength of between-domains relations for academic emotions should be found for disparate academic domains (e.g., mathematics and English) rather than for similar academic domains (e.g., mathematics and physics).

\section{Within-Domain Relations of Academic Emotions}

Hypothesis 2a-Strength of within-domain relations. We anticipated a within-domain pattern of relations between distinct emotions reflecting the two theoretical affect dimensions of valence and activation (Watson \& Tellegen, 1985). In particular, as we did not include any positive deactivating emotion in the present study, we expected that enjoyment and pride (positive-activating), anxiety and anger (negative-activating), and boredom (negativedeactivating) could be separated along the dimensions of valence and activation.

Hypothesis $2 b$-Within-domain relations as a function of academic domain. Research is lacking concerning the consistency of within-domain relations for academic emotions across domains. When we compare the within-domain relations of school-age students in the context of mathematics, as reported by Goetz (2004), with the relational pattern found for university students in studies by Pekrun et al. (2004), the results show a relatively consistent pattern. On the basis of these two sets of findings, we assumed that the pattern of within-domain relations would be relatively stable across domains.

Hypothesis 2c-Within-domain relations as a function of grade level. Given that the study by Bong (2001) found stability in the within-domain relations for motivational constructs across different grade levels (middle vs. high school students), we expected that within-domain relations of academic emotions would also be stable across grade levels. However, as we found no previous research addressing this issue with respect to students' emotions, our study is exploratory in nature concerning this research question.

\section{Method}

\section{Sample and Data Collection}

The sample consisted of 542 German high school students (56\% female) with a mean age of 15.77 years $(S D=1.66)$, including 307 students $(53 \%$ female) from Grade 8 (mean age $=14.42$ years, $S D=0.61 ;$ range $=13.25-16.50)$ and 235 students $(60 \%$ female $)$ from Grade 11 (mean age $=17.53$ years, $S D=0.60$; range $=$ 16.33-19.67). Data collection took place during the second part of the academic year (April and May 2005) and was conducted by trained testing personnel using fully standardized student questionnaires. Participants were tested in a classroom setting and took part on a voluntary basis. To prevent participants from explicitly focusing on comparisons among the different subject areas, we located items referring to different domains in different parts of the booklets. There was a negligible number of missing questionnaire data due to student nonresponse $(0.2 \%$ missing data at the item level).

\section{Measurement of Discrete Emotions in Different Domains}

To measure enjoyment, pride, anxiety, anger, and boredom in the domains of mathematics, physics, German, and English, we adapted emotion scales concerning students' feelings toward classroom learning (i.e., as opposed to test taking or homework) from the mathematics version of the Achievement Emotions Questionnaire (Pekrun, Goetz, \& Frenzel, 2005). We used parallel item wordings for the assessment of five emotional experiences in four different domains ( 4 items per scale). Consequently, 80 emotion items were used in the questionnaire ( 5 emotions $\times 4$ domains $\times$ 4 items per scale). Sample items were as follows: "I am looking forward to [domain] classes" for enjoyment, "I am proud of the contributions I make in [domain] classes" for pride, "I feel tense and nervous in [domain] classes" for anxiety, "I am angry in [domain] classes" for anger, and "I get bored in [domain] classes" for boredom. The response format consisted of a 5-point Likert scale ranging from 1 (strongly disagree) to 5 (strongly agree).

In Appendix A, the means, standard deviations, and Cronbach's alphas are provided for all 20 emotion scales $(5$ emotions $\times 4$ domains), and are presented separately for the two grade levels. Given that items were strictly parallel across the four academic domains, means and standard deviations of the scales referring to the same emotional experience in different domains can be compared directly (e.g., enjoyment in mathematics and enjoyment in physics). For a given emotion, scores of the 8th and 11th grade samples can also be directly compared. However, it would not be meaningful to compare means and standard deviations for scales referring to different emotions, as scale items referring to different emotions were not parallel with respect to item wording (e.g., items for enjoyment and anger). Standardized alphas for the emotion scales ranged from .72 to $.92(M d n=.88)$ in the Grade 8 sample and from .66 to $.93(M d n=.88)$ in the Grade 11 sample. With two exceptions (anxiety and anger in German, each Grade 11), all of the altogether 40 alphas were above .70 . Zero-order correlations among all of our measures are presented in Appendix B separately for the two grade levels. 
Table 1

Between-Domains Relations of Academic Emotion Constructs-Characteristics of the Structural Equation Models

\begin{tabular}{|c|c|c|c|c|c|c|c|c|c|c|}
\hline \multirow[b]{2}{*}{ Model } & \multicolumn{5}{|c|}{ Grade 8} & \multicolumn{5}{|c|}{ Grade 11} \\
\hline & $x^{2}$ & $d f$ & NNFI & CFI & RMSEA & $x^{2}$ & $d f$ & NNFI & CFI & RMSEA \\
\hline Enjoyment & 208.61 & 122 & .96 & .97 & .051 & 151.70 & 122 & .98 & .99 & .032 \\
\hline Pride & 219.28 & 122 & .95 & .97 & .054 & 258.92 & 122 & .92 & .95 & .070 \\
\hline Anxiety & 218.76 & 122 & .94 & .96 & .054 & 216.61 & 122 & .93 & .95 & .059 \\
\hline Anger & 285.93 & 122 & .88 & .92 & .071 & 250.10 & 122 & .87 & .92 & .068 \\
\hline Boredom & 218.22 & 118 & .95 & .97 & .056 & 185.53 & 118 & .95 & .97 & .050 \\
\hline
\end{tabular}

Note. $\quad \mathrm{NNFI}=$ Bentler-Bonett nonnormed fit index $\mathrm{CFI}=$ comparative fit index; RMSEA $=$ root-mean-square error of approximation.

\section{Academic Achievement}

Achievement in mathematics, physics, German, and English was assessed by means of students' midterm grades. In the German school system, midterm grades are typically the result of one written exam administered in each subject area over the course of the first half of an academic year, combined with scores on course-specific oral examinations. Grades range from 1 (very good) to 6 (insufficient), with higher numbers representing poorer achievement. To make coefficients involving these achievement measures interpretable in a more intuitive manner, we inverted students' grades so that high numbers indicated better performance. Means and standard deviations for the achievement data are presented separately for Grade 8 and Grade 11 students in Appendix A, and zero-order correlations among all achievement measures are outlined in Appendix B.

\section{Data Analysis}

For analyzing between- and within-domain relations, we used structural equation modeling, which provided disattenuated relationships between the variables under investigation. We used multilevel analysis for comparing the strength of between-domains relations across constructs and grade levels as well as the strength of within-domain relations across domains and grade levels. Multilevel analyses provide one single score indicating the strength of relationships for each of the between- and within-domain analyses: one score for each emotion construct and achievement showing the strength of between-domains relations for these constructs, and one score for each domain showing the strength of within-domain relations for this domain. ${ }^{1}$

\section{Results}

\section{Between-Domains Analyses}

Strength of between-domains relations (Hypothesis 1a). To analyze between-domains relations of academic emotions, we used structural equation modeling (LISREL 8.72; Jöreskog \& Sörbom, 2002). We created one model for each of the five emotions (enjoyment, pride, anxiety, anger, boredom) and analyzed them separately for the Grade 8 and Grade 11 samples. For each model, latent domain-specific discrete emotion factors were constructed. Because parallel item wordings were used across the domainspecific emotion measures, correlated uniquenesses between parallel items were included. Parallel item wordings represent latent method factors, and modeling correlated uniquenesses between items with parallel wordings controlled for the potential effects of these method factors in our models (see Marsh et al., 1992; Marsh, Byrne, \& Yeung, 1999). Concerning boredom, four additional correlated uniquenesses were needed to achieve satisfactory model fit (in both the 8 th grade and the 11 th grade samples). ${ }^{2}$

To investigate the convergent and divergent validity of the domain-specific emotion constructs, we also included achievement outcomes (as manifest variables) in each of our models (Marsh, 1989; Marsh \& Yeung, 1996). Altogether, 10 models were created (5 emotions $\times 2$ samples), with each model consisting of four latent emotion factors (domain-specific discrete emotions) and four manifest achievement factors (academic achievement in the four domains). Table 1 shows the fit indexes for the structural equation models (for detailed descriptions of the fit indexes used, see Tucker \& Lewis, 1973, nonnormed fit index; Bentler, 1990, comparative fit index; Steiger \& Lind, 1980, root-mean-square error of approximation). The fit of all models was acceptable, indicating that it was meaningful to let items referring to the same emotional experiences load on latent factors representing the specific domain to which they referred.

Table 2 shows the interrelations among the latent domain- and emotion-specific factors as well as the interrelations between these factors and the achievement scores. Even disattenuated, the interrelations among the domain- and emotion-specific factors were relatively weak, indicating generally weak between-domains relations for the emotion constructs. With the exception of substantial relations between emotions in mathematics and physics and the relatively strong relations between pride in English and German, all coefficients were below .35 in the Grade 8 sample and below .20 in the Grade 11 sample. The relations between emotions in mathematics and physics ranged from .38 to .61 in the Grade 8 sample and from .48 to .64 in the Grade 11 sample. Given that

\footnotetext{
${ }^{1}$ An integrated multitrait-multimethod analysis of both between- and within-domain relations is not feasible with data such as ours, because the number of parameters to be estimated would exceed the number of observations. Therefore, separate models had to be constructed (Marsh, Byrne, \& Craven, 1992).

${ }^{2}$ In particular, correlated uniquenesses between two items that both referred to the motivational component of boredom were added in the boredom models for each of the four domains. The shared motivational contents of these items are assumed to underlie their common variance that is not explained by the latent domain-specific emotion factors.
} 


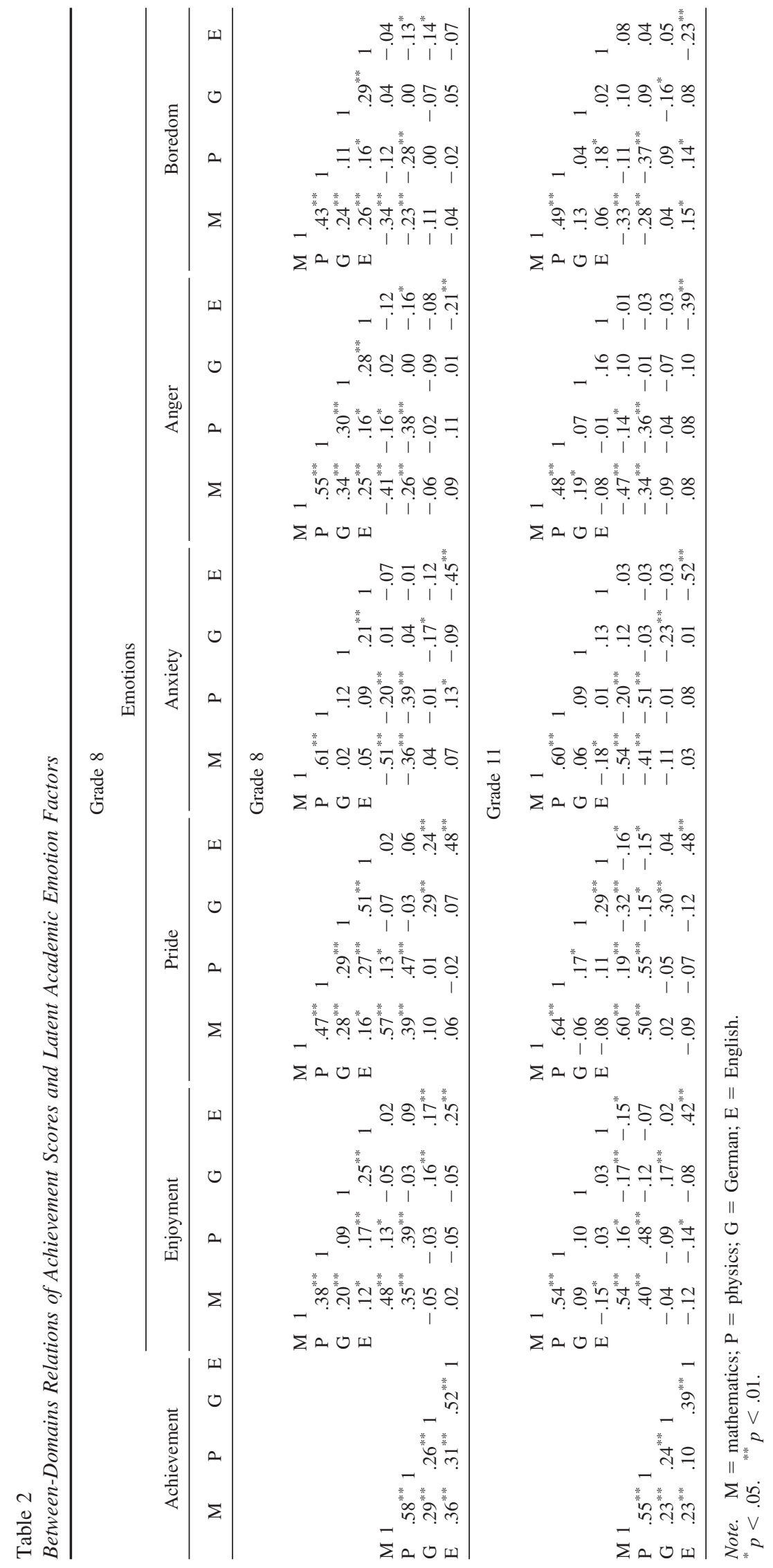


these coefficients were corrected for unreliability, thus representing relationships at the latent level, these findings show that emotional experiences were quite different across domains, even two similar domains, such as mathematics and physics.

Concerning relations between latent domain-specific emotion and achievement scores, with few exceptions, the strongest relations were found between emotions and achievement scores referring to the same domain (see Table 2). Overall, positive relations were found between positive emotions (enjoyment, pride) and achievement, and negative relations were found between negative emotions (anxiety, anger, boredom) and achievement. Altogether, the pattern of correlations between emotions and achievement scores indicates high convergent and discriminant validity for the latent domain-specific emotion factors and further strengthens the assumption of weak between-domains relationships.

Between-domains relations as a function of emotion type and grade level (Hypotheses 1b, 1c). For analyzing the strength of between-domains relations of academic emotions as a function of type of emotion and grade level, we conducted a multilevel analysis using the software Mplus 4.0 (Muthén \& Muthén, 2006). We adopted multilevel analysis as it provides one score for each emotion construct and achievement showing the strength of between-domains relations for these constructs and one single score for each domain showing the strength of within-domain relations for this domain. We created a fully unconditional threelevel model that provided information about the outcome variability on each of the three levels (see Figure 1, emotion section; Raudenbush \& Bryk, 2002). We posited that the relative sizes of proportions of these variances would allow for inferences about the degree of homogeneity (see Hox, 2002) and, consequently, about the strength of between-domains relations of each emotion (see below). We created these three-level models separately for the Grade 8 and Grade 11 samples to allow for comparisons of between-domains relations across the two age groups.

In the three-level hierarchical model (see Figure 1, emotion section), the variance of the outcome variable $Y_{i j k}$ is defined as variance of the domain- and emotion-specific item $i$ (Level 1) nested within the domain-specific discrete emotion scale $j$ (Level 2) nested within the domain-general discrete emotion score of person $k$ (Level 3). That is, for each of the five discrete emotions, each person had one domain-general emotion score (Level 3 units), four domain-specific emotion scores (Level 2 units), and scores on four individual scale items for each domain (Level 1 units).

The variance of $Y_{i j k}$ can be portioned into three parts (see Raudenbush \& Bryk, 2002): $\operatorname{Var}\left(Y_{i j k}\right)=\operatorname{Var}\left(u_{O o k}+r_{O j k}+e_{i j k}\right)=\tau_{\beta}+\tau_{\pi}+$ $\sigma^{2}$, with $u_{O o k}$ being the Level 3 residuum, $r_{O j k}$ being the Level 2 residuum, and $e_{i j k}$ being the Level 1 residuum. On the basis of these variance components, we can calculate an index $h(\mathrm{~d})$, where $d$ stands for domain, of the homogeneity of the scales referring to the same emotion but different domains: $h(\mathrm{~d})=\tau_{\beta} /\left(\tau_{\beta}+\tau_{\pi}\right)$. That is, $h(\mathrm{~d})$ reflects the proportion of the Level 3 variance in the total variance of Levels 2 and 3. Consequently, $h(d)$ is an index for the homogeneity of Level 2 constructs that takes the heterogeneity of Level 1 constructs (items within scales) into account. In other words, $h(\mathrm{~d})$ indicates the strength of between-domains relations of the domain-specific discrete emotion scales when the heterogeneity (unreliability) of the items within scales is controlled. The higher the $h(\mathrm{~d})$ value is, the stronger the between-domains relations for the domain-specific discrete emotions scales are.
To validate our results with respect to achievement outcomes, we compared grade-related differences in the strength of betweendomains relations for academic emotions with the grade-related differences in the strength of between-domains relations for academic achievement. Thus, we included achievement scores (midterm grades) in our multilevel analyses. It is important to note that Level 1 units of achievement, namely the results of specific written and oral exams, were not available in the present study. Thus, we calculated a two-level hierarchical model in which the lower level referred to the domain-specific achievement scales (midterm grades in mathematics, physics, German, and English) and the higher level referred to a domain-general achievement score of a person (average achievement across domains). To make the level definitions consistent for emotions and achievement (see Figure 1, emotion and achievement sections), in our two-level hierarchical achievement model, we labeled the lower level as Level 2 and the higher level as Level $3 .^{3}$

Table 3 shows the results of our multilevel analysis of the between-domains relationships of emotions and achievement, as moderated by emotion type and students' grade level (Hypotheses $1 \mathrm{~b}$ and 1c). As an index of the strength of between-domains relations for the domain-specific emotion scales, $h(\mathrm{~d})$ showed that there were differences based on emotion type. Enjoyment and anxiety showed the weakest, and pride the strongest, betweendomains relations in both samples. However, all of the differences were weak, even though some were statistically significant. ${ }^{4}$ Differences between enjoyment and pride as well as between pride and anxiety were significant in both samples (technical details concerning the testing for significant differences are described in Appendix C).

Concerning differences based on grade level involving the between-domains relations of students' emotions, betweendomains relations were clearly stronger in the Grade 8 sample as compared with the Grade 11 sample. $h(\mathrm{~d})$ ranged from .22 to .38 in the Grade 8 sample $(M d n=.30)$ and from .06 to .20 in the Grade 11 sample $(M d n=.11)$. For each of the five emotions, differences in $h(\mathrm{~d})$ were statistically significant across the two samples ( $p<.01$ for enjoyment, pride, anxiety, and anger; $p<.05$ for boredom). Concerning achievement scores, we found a similar result. $h(\mathrm{~d})$ was significantly stronger in Grade 8 than in Grade 11: $h(\mathrm{~d})=.37$ in Grade 8 and .26 in Grade $11(p<.01)$. This finding

\footnotetext{
${ }^{3}$ Although calculating a homogeneity index for achievement on the basis of a two-level model allowed a comparison of this index across the two samples, the homogeneity indexes for achievement outcomes cannot be directly compared with those for emotional experiences. This is because only a single indicator of achievement was available in each domain. Therefore, it was not possible to account for unreliability in the achievement outcomes when we calculated the homogeneity index. As the different emotions were measured with multiple items, unreliability of the Level 1 units (items) could be taken into account when we calculated the emotion-related homogeneity index.

${ }^{4}$ In the Grade 8 sample, $h(\mathrm{~d})$ differed significantly between enjoyment and pride $(p<.01)$, enjoyment and anger $(p<.01)$, pride and anxiety $(p<.01)$, anxiety and anger $(p<.01)$, and anger and boredom $(p<.05)$ In the Grade 11 sample, $h(\mathrm{~d})$ differed significantly for enjoyment and pride $(p<.01)$, enjoyment and boredom $(p<.05)$, pride and anxiety $(p<.01)$, and anxiety and boredom $(p<.05)$.
} 


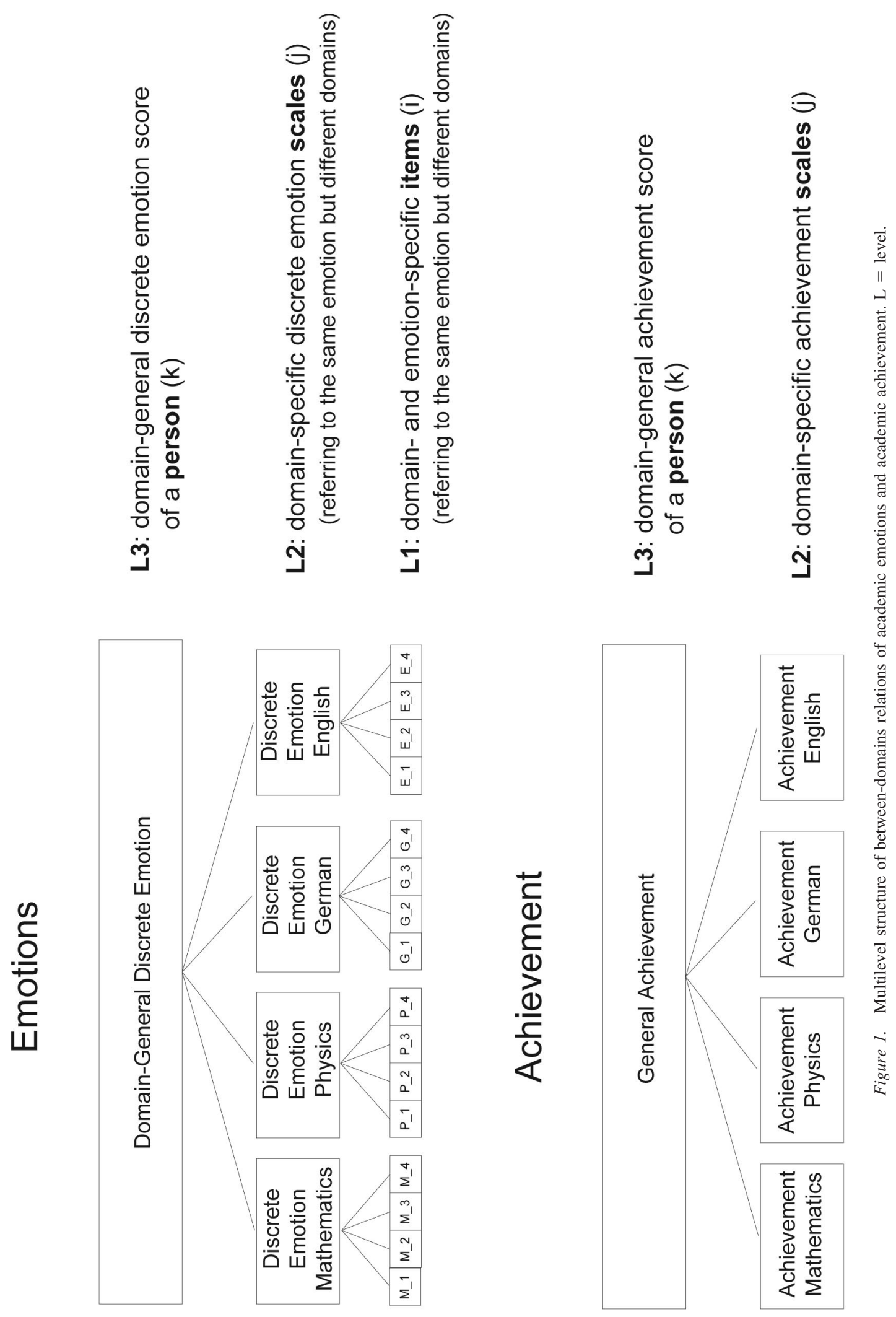


Table 3

Results of Multilevel Analysis on the Between-Domains Relations of Discrete Academic Emotions and Academic Achievement

\begin{tabular}{|c|c|c|c|c|}
\hline \multirow[b]{2}{*}{ Variable } & \multicolumn{3}{|c|}{ Variance components } & \multirow[b]{2}{*}{$\begin{array}{l}\text { Homogeneity of } \\
\text { domains: Homogeneity } \\
\text { index } h(\mathrm{~d})\end{array}$} \\
\hline & $\begin{array}{l}\text { Level } 3\left(\tau_{\beta}\right) \text { : } \\
\text { Domain-transcending } \\
\text { scores of persons }\end{array}$ & $\begin{array}{c}\text { Level } 2\left(\tau_{\pi}\right): \\
\text { Domain-specific } \\
\text { scales within persons }\end{array}$ & $\begin{array}{c}\text { Level } 1\left(\sigma^{2}\right) \text { : } \\
\text { Domain-specific } \\
\text { items within scales }\end{array}$ & \\
\hline \multicolumn{5}{|c|}{ Grade 8} \\
\hline Enjoyment & .221 & .766 & .511 & .22 \\
\hline Pride & .358 & .598 & .537 & .38 \\
\hline Anxiety & .171 & .552 & .539 & .24 \\
\hline Anger & .259 & .450 & .819 & .37 \\
\hline Boredom & .299 & .713 & .567 & .30 \\
\hline Achievement & .295 & .511 & & .37 \\
\hline \multicolumn{5}{|c|}{ Grade 11} \\
\hline Enjoyment & .106 & .990 & .410 & .08 \\
\hline Pride & .202 & .782 & .490 & .20 \\
\hline Anxiety & .050 & .740 & .620 & .06 \\
\hline Anger & .080 & .642 & .927 & .11 \\
\hline Boredom & .185 & .878 & .515 & .17 \\
\hline Achievement & .249 & .697 & & .26 \\
\hline
\end{tabular}

Note. Homogeneity index was calculated as follows: $h(\mathrm{~d})=\tau_{\beta} /\left(\tau_{\beta}+\tau_{\pi}\right)$.

suggests that the between-domains associations for achievement scores were stronger in younger students.

\section{Within-Domain Analyses}

Strength of within-domain relations of academic emotions (Hypothesis $2 a$ ). Similar to the analysis of between-domains relations, we used structural equation modeling for analyzing the strength of within-domain relations of academic emotions. This was done separately for each of the four domains. For each of these domains (mathematics, physics, English, German), latent factors referring to enjoyment, pride, anxiety, anger, and boredom within the domain were created. Again, the models were assessed separately for the Grade 8 and 11 samples, which resulted in a total of eight models (4 domains $\times 2$ samples).

Table 4 shows the fit indexes for the eight models. As with the models for between-domains relations, correlated uniquenesses between the second and third boredom items were included in each model. The models showed acceptable to marginally acceptable overall fit. The reduced fit indicated that some side loadings were not accounted for in these models. In other words, some items might have loaded on more than one latent emotion-specific factor, thus indicating a degree of multiemotionality in some items. This assumption is supported by the modification indexes from LISREL 8.72, which indicated a decrease in chi-square when paths from items to multiple latent emotion factors were added.

Our results are similar to those of Bong (2001), which showed acceptable fit for structural equation models assessing the between-domains relations of motivational constructs but only marginally acceptable fit for structural equation models of withindomain relations. It is important to note, however, that traditional cutoff values for structural equation modeling fit indexes are rules of thumb that are largely contingent on the standards set by previous research in a given field (Bollen, 1989) and are limited in their statistical justification (Marsh, Hau, \& Wen, 2004). When selecting an appropriate standard against which to compare our fit indexes, we used Bong's (2001) study of motivational constructs as a reference. Following Bong's (2001) analysis, we proceeded to use the present models to assess the strength of within-domain relations of the emotion constructs.

Table 4

Within-Domain Relations of Academic Emotion Constructs-Characteristics of the Structural Equation Models

\begin{tabular}{|c|c|c|c|c|c|c|c|c|c|c|}
\hline \multirow[b]{2}{*}{ Domain } & \multicolumn{5}{|c|}{ Grade 8} & \multicolumn{5}{|c|}{ Grade 11} \\
\hline & $x^{2}$ & $d f$ & NNFI & CFI & RMSEA & $\chi^{2}$ & $d f$ & NNFI & CFI & RMSEA \\
\hline Mathematics & 692.78 & 159 & .88 & .90 & .107 & 574.92 & 159 & .89 & .91 & .107 \\
\hline Physics & 531.47 & 159 & .91 & .93 & .090 & 597.67 & 159 & .87 & .89 & .110 \\
\hline German & 369.70 & 159 & .90 & .92 & .068 & 418.91 & 159 & .88 & .90 & .085 \\
\hline English & 593.41 & 159 & .87 & .89 & .097 & 555.07 & 159 & .88 & .90 & .104 \\
\hline
\end{tabular}

Note. $\mathrm{NNFI}=$ Bentler-Bonett nonnormed fit index; $\mathrm{CFI}=$ comparative fit index; RMSEA $=$ root-mean-square error of approximation . 
Table 5 presents the correlations among the latent emotion factors for each of the four domains separately for the two samples. All of the correlations between positive and negative emotions were negative. The intercorrelations between the two positive emotions (enjoyment, pride) as well as among the three negative emotions (anxiety, anger, boredom) were positive. Conspicuously strong correlations were found between boredom and anger (range $=.81$ to .90 , across domains and grade levels) and between enjoyment and boredom (range $=-.76$ to -.91 , across domains and grade levels). However, given that these coefficients were corrected for unreliability and thus represented the highest possible coefficients derivable from these data, it nonetheless seems warranted to conceptually distinguish between these different academic emotions.

Within-domain relations as a function of domain and grade level (Hypotheses $2 b$ and $2 c$ ). For analyzing domain- and graderelated differences in within-domain relations, we used the same multilevel analysis as for analyzing between-domains relations (see above). However, achievement scores were not included, as only a single achievement indicator in each domain was available. We used relative proportions of variance as indexes for the strength of homogeneity of the different discrete emotions within a specific domain. Creating separate three-level models for our 8th and 11th grade samples further allowed us to compare the amount of within-domain homogeneity of our emotion constructs both within and across the two age groups.

In our three-level hierarchical model (see Figure 2), the variance of $Y_{i j k}$-expressed as $\operatorname{Var}\left(Y_{i j k}\right)$-was defined as variance of the domain- and emotion-specific item $i$ (Level 1) nested within the domain-specific discrete emotion scale $j$ (Level 2) nested within the emotion-general domain-specific score of person $k$ (Level 3). As enjoyment and pride are positive emotions and anxiety, anger, and boredom negative emotions, it would not have been meaningful to aggregate all five emotions into one score. Thus, we inverted all negative emotion items (items referring to anxiety, anger, and boredom) for the analysis of within-domain relations. Consequently, all items can be interpreted as indicators for the presence of positive emotions or, conversely, the absence of negative emotions.

Consistent with our analyses of between-domains relations, we calculated $h(\mathrm{e})$, where $e$ stands for emotion, to indicate the strength of within-domain relations for scales referring to the same domain but different emotions. Similar to the analysis of between-domains relations, $h(\mathrm{e})$ can be calculated as follows: $h(\mathrm{e})=\tau_{\beta} /\left(\tau_{\beta}+\tau_{\pi}\right)$. It shows the strength of within-domain relations of the domainand emotion-specific scales when heterogeneity (unreliability) among the items within scales is controlled. The higher $h(\mathrm{e})$ is, the stronger the within-domain relations of the emotion-specific scales in a given domain are.

Table 6 shows results of our multilevel analysis on withindomain relations of academic emotions (Hypotheses $2 b$ and 2c). The comparison of $h(\mathrm{e})$ within the two samples shows that the strength of within-domain relationships differed strongly as a function of academic domain. With the single exception of the difference in $h(\mathrm{e})$ between physics and English in Grade 11, all of the differences in $h(\mathrm{e})$ were statistically significant $(p<.05)$ in both samples (technical details concerning the testing for significant differences are described in Appendix C). In both samples, the strongest within-domain relations were found for mathematics, followed by physics, English, and German. Within-domain relations in German were by far the weakest. This pattern of differences was consistent across grade levels. The $h(\mathrm{e})$ values as indicators of the strength of within-domain relations were nearly the same for the Grade 8 and Grade 11 samples. The differences in $h(\mathrm{e})$ across the two samples did not reach significance for any of the four domains $(p>.05)$. This indicates that the relations among enjoyment, pride, anxiety, anger, and boredom within the different domains were similar in both grade levels.

\section{Discussion}

\section{Between-Domains Relations of Academic Emotions}

Domain specificity of students' academic emotions. The results of the present study are consistent with our assumptions

Table 5

Within-Domain Relations of Latent Academic Emotion Factors

\begin{tabular}{|c|c|c|c|c|c|c|c|c|c|c|c|c|c|c|c|c|c|c|c|c|c|c|c|}
\hline \multicolumn{24}{|c|}{ Grade 8} \\
\hline \multicolumn{6}{|c|}{ Mathematics } & \multicolumn{6}{|c|}{ Physics } & \multicolumn{6}{|c|}{ German } & \multicolumn{6}{|c|}{ English } \\
\hline & $\mathrm{Ej}$ & $\operatorname{Pr}$ & $\mathrm{Ax}$ & An & Bo & & $\mathrm{Ej}$ & $\operatorname{Pr}$ & $\mathrm{Ax}$ & An & Bo & & $\mathrm{Ej}$ & $\mathrm{Pr}$ & $\mathrm{Ax}$ & An & Bo & & $\mathrm{Ej}$ & $\operatorname{Pr}$ & $\mathrm{Ax}$ & An & Bo \\
\hline $\mathrm{Ej}$ & 1 & & & & & $\mathrm{Ej}$ & 1 & & & & & $\mathrm{Ej}$ & 1 & & & & & $\mathrm{Ej}$ & 1 & & & & \\
\hline $\operatorname{Pr}$ & .81 & 1 & & & & $\mathrm{Pr}$ & .83 & 1 & & & & $\operatorname{Pr}$ & .57 & 1 & & & & $\mathrm{Pr}$ & .73 & 1 & & & \\
\hline$A x$ & -.67 & -.60 & 1 & & & $A x$ & -.59 & -.53 & 1 & & & $\mathrm{Ax}$ & -.44 & -.23 & 1 & & & $\mathrm{Ax}$ & -.45 & -.44 & 1 & & \\
\hline An & -.76 & -.56 & .74 & 1 & & An & -.77 & -.57 & .84 & 1 & & An & -.79 & -.27 & .61 & 1 & & An & -.75 & -.48 & .66 & 1 & \\
\hline Bo & -.76 & -.50 & .50 & .85 & 1 & Bo & -.81 & -.50 & .57 & .90 & 1 & Bo & -.88 & -.33 & .35 & .87 & 1 & Bo & -.83 & -.41 & .30 & .81 & 1 \\
\hline
\end{tabular}

Grade 11

\begin{tabular}{|c|c|c|c|c|c|c|c|c|c|c|c|c|c|c|c|c|c|c|c|}
\hline $\mathrm{Ej}$ & & & & $\mathrm{Ej}$ & 1 & & & & $\mathrm{Ej}$ & 1 & & & & & $\mathrm{Ej}$ & 1 & & & \\
\hline .85 & 1 & & & $\operatorname{Pr}$ & .86 & 1 & & & $\operatorname{Pr}$ & .66 & 1 & & & & Pr & .82 & 1 & & \\
\hline-.70 & -.69 & 1 & & $A x$ & -.60 & -.55 & 1 & & $A x$ & -.28 & -.22 & 1 & & & $A x$ & -.58 & -.56 & 1 & \\
\hline-.86 & -.68 & .821 & & An & -.76 & -.60 & .811 & & An & -.75 & -.27 & .59 & 1 & & An & -.72 & -.42 & .64 & 1 \\
\hline-.81 & -.75 & $.49 \quad .84$ & 1 & Bo & -.81 & -.63 & $\begin{array}{ll}.56 & .81\end{array}$ & 1 & Bo & -.91 & -.45 & .24 & .81 & 1 & Bo & -.77 & -.40 & .29 & .82 \\
\hline
\end{tabular}

Note. All coefficients are significant $(p<.01) . \mathrm{Ej}=$ enjoyment; $\mathrm{Pr}=$ pride; $\mathrm{Ax}=$ anxiety; An $=$ anger; $\mathrm{Bo}=$ boredom. 
ij

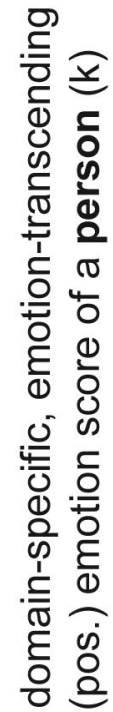



离 吉 की

Ð

屯

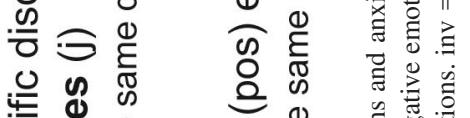

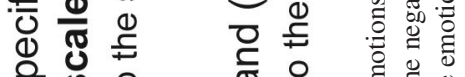

क力

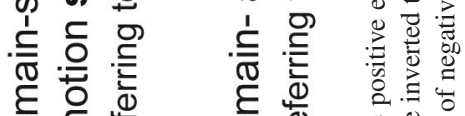

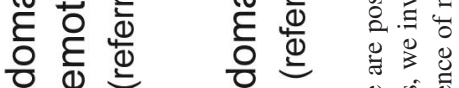

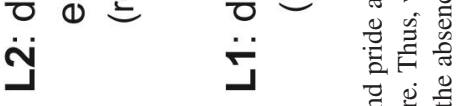

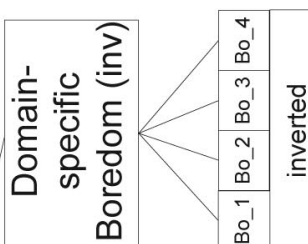

政

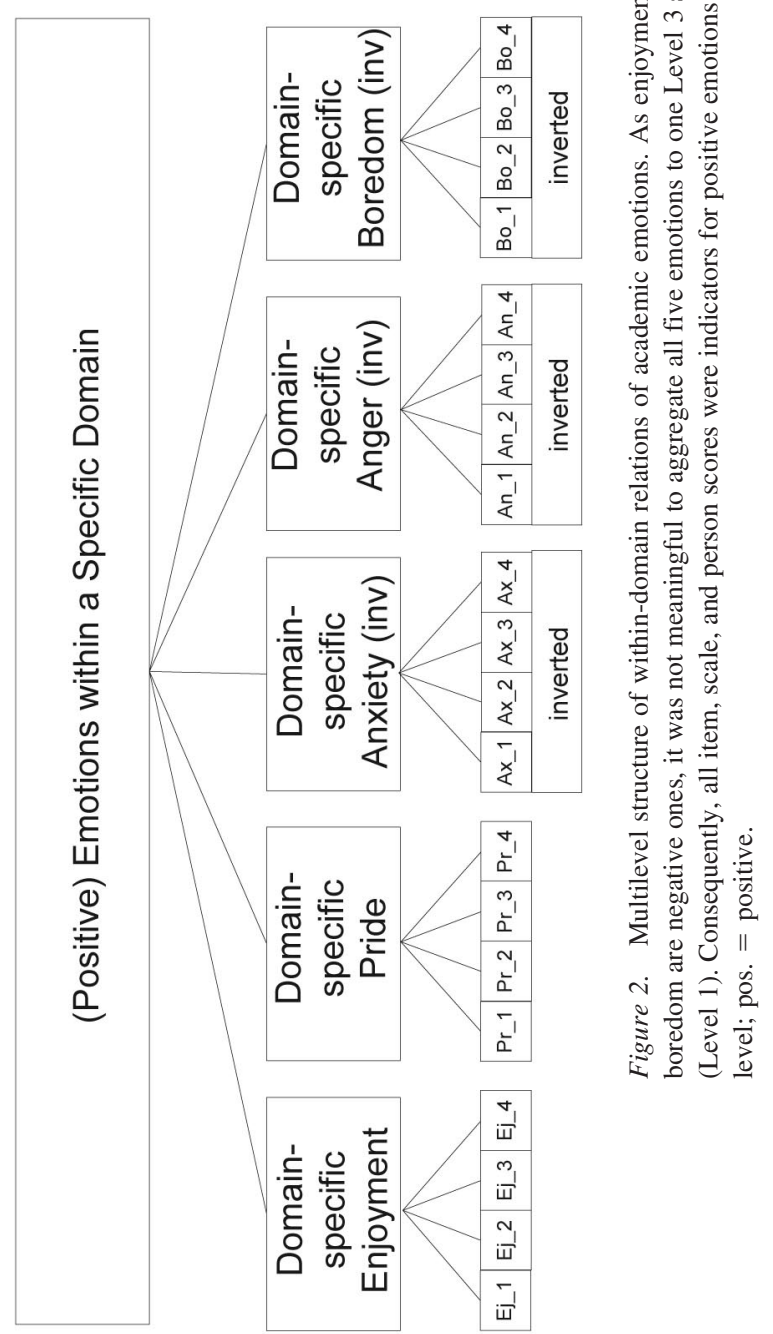


Table 6

Results of Multilevel Analysis on the Within-Domain Relations of Discrete Academic Emotions

\begin{tabular}{|c|c|c|c|c|}
\hline \multirow[b]{2}{*}{ Academic subject } & \multicolumn{3}{|c|}{ Variances } & \multirow[b]{2}{*}{$\begin{array}{l}\text { Homogeneity of } \\
\text { emotions: Homogeneity } \\
\text { index } h(\mathrm{e})\end{array}$} \\
\hline & $\begin{array}{c}\text { Level } 3\left(\tau_{\beta}\right) \text { : } \\
\text { Emotion-transcending } \\
\text { scores of persons }\end{array}$ & $\begin{array}{c}\text { Level } 2\left(\tau_{\pi}\right) \text { : } \\
\text { Emotion-specific } \\
\text { scales within persons }\end{array}$ & $\begin{array}{c}\text { Level } 1\left(\sigma^{2}\right) \text { : } \\
\text { Emotion-specific } \\
\text { items within scales }\end{array}$ & \\
\hline \multicolumn{5}{|c|}{ Grade 8} \\
\hline Mathematics & .745 & .581 & .623 & .56 \\
\hline Physics & .628 & .657 & .559 & .49 \\
\hline German & .223 & .840 & .663 & .21 \\
\hline English & .323 & .527 & .535 & .38 \\
\hline \multicolumn{5}{|c|}{ Grade 11} \\
\hline Mathematics & .758 & .517 & .669 & .59 \\
\hline Physics & .597 & .635 & .587 & .49 \\
\hline German & .173 & .915 & .611 & .16 \\
\hline English & .456 & .684 & .502 & .40 \\
\hline
\end{tabular}

Note. All negative emotion items (items referring to anxiety, anger, and boredom) were inverted for this analysis. Consequently, all items were indicators of positive emotional experiences. Homogeneity index was calculated as follows: $h(\mathrm{e})=\tau_{\beta} /\left(\tau_{\beta}+\tau_{\pi}\right)$.

(Hypothesis 1a) and previous findings that indicate a largely domain-specific organization of academic emotions. In particular, these findings corroborate assumptions derived from appraisal theories of emotions, such as Pekrun's $(2000,2006)$ control-value theory of achievement emotions: To the extent that appraisals are organized in domain-specific ways, the emotions aroused by these appraisals should also be domain specific. Given that previous research has shown domain specificity for students' achievementrelated appraisals (i.e., self-efficacy expectancies, self-concepts of ability, task values, and achievement goals), one important corollary of Pekrun's control-value theory is that students' academic emotions should be characterized by weak between-domains relations as well. The findings of the present study corroborate this assumption.

Correlations were stronger for emotions in similar subject domains (the quantitative domains of mathematics and physics and the verbal domains of German and English), as compared with emotions experienced in more disparate domains. However, none of the correlation coefficients was large enough to cast doubt on the domain-specific organization of academic emotions. Furthermore, the assumption of domain specificity was clearly supported by the pattern of correlations between emotions and achievement scores. These results also provide strong support for the convergent and divergent validity of our domain-specific emotion scales (cf. Marsh \& Yeung, 1996).

The weak between-domains relations found in this study suggest that it may be inappropriate to conceptualize students' academic emotions as domain-generalized constructs, especially with respect to high school students. Rather, these findings suggest that domain-specific constructs are needed to represent students' academic emotions. Relevant academic emotions include not only anxiety but also other negative achievement-related emotions (e.g., shame, anger) as well as positive emotions such as enjoyment and pride.

Between-domains relations as a function of emotion type and grade level. Our multilevel analyses showed that the strength of between-domains relations differed across the five emotions as- sessed (see Hypothesis 1b). However, although some of these differences reached statistical significance, they can be described as relatively weak. Concerning anxiety, it is important to note that this emotion did not seem to be more domain general than enjoyment, pride, anger, and boredom, even though anxiety has frequently been discussed as a domain-transcending emotion (e.g., Zeidner, 1998). Indeed, anxiety and enjoyment showed the lowest degree of between-domains associations at both grade levels in the present study. This finding diverges from the results of our two preliminary studies (Goetz et al., 2006; Pekrun et al., 2002b), in which anxiety was found to show stronger between-domains relations than enjoyment and boredom. However, in contrast to the multi-item measures used in the present study, single-item measures were used in our previous investigations, which raises concerns as to the validity and psychometric quality of the measures used. The relatively strong between-domains relations found in our earlier studies might have been due, in part, to the low validity of single-item scales. In other words, these single-item scales might have assessed a more global construct of anxiety and therefore might have overestimated the strength of between-domains relationships of students' domain-related anxiety.

In line with our assumptions (Hypothesis 1c), multilevel analysis showed that between-domains relations of academic emotions were significantly weaker in older students. Further, our results are consistent with Marsh and Ayotte's (2003) differential distinctiveness hypothesis, which states that constructs that already show between-domains differences in young children should become more differentiated with age. Conversely, this hypothesis suggests that one should observe much less age-related decline in correlations between constructs that are strongly associated in young children. Indeed, in the present study, the relations between emotions pertaining to quantitative and verbal subjects were weaker, or even negative, in Grade 11 relative to Grade 8. Similarly, the relations between emotions in the two language domains (German and English), which were relatively weak in Grade 8, were even weaker in Grade 11. In contrast, the between-domains relations of emotions involving mathematics and physics were relatively 
strong in Grade 8 and were nearly as strong or stronger in Grade 11. As such, our results with respect to academic emotions are consistent with the differential distinctiveness hypothesis as applied to academic self-concepts.

\section{Within-Domain Relations of Academic Emotions}

Strength of within-domain relations. Our results only partially confirm assumptions based on a categorization of emotional experiences according to the dimensions of valence and activation (Watson \& Tellegen, 1985). On the basis of this prominent approach, we assumed that enjoyment and pride (positiveactivating), anxiety and anger (negative-activating), and boredom (negative-deactivating) could be empirically differentiated (see Hypothesis 2a). However, in the present results, anger seemed to be more strongly related to boredom than to anxiety. Pekrun et al. (2002a) found a similar pattern of relationships for academic emotions experienced by university students.

These authors explained their results by arguing that emotions cluster together if they share antecedents or if they are caused by correlated antecedents. In particular, as seen from the perspective of appraisal theories, anxiety is often the result of low levels of perceived control, whereas anger and boredom can emerge when students' perceived control is greater (Pekrun, 2006; Roseman, Antoniou, \& Jose, 1996). From an instructional perspective, it is also possible that teaching styles that do not match students' needs and capabilities can arouse both boredom and anger. An alternative explanation might be that these two emotions are often processrelated in an academic context (i.e., aroused by ongoing classroom instruction and academic activities), whereas achievement-related anxiety is a more outcome-oriented emotion pertaining to anticipated failure and its consequences.

Within-domain relations as a function of domain and grade level. Unexpectedly, multilevel analysis revealed that the strength of relations among discrete emotional experiences was significantly different across domains (see Hypothesis $2 \mathrm{~b}$ ). This was consistently so across grade levels. The strongest withindomain relations were found for the domain of mathematics and the weakest were found for the domain of German. One explanation might be that German as a subject is more heterogeneous or, in other words, "fuzzier" than the subject of mathematics. For example, German classes involve various areas of potential interest and may include study material ranging from poems and biographies to technical or news reports on controversial topics. In contrast, the topics covered in mathematics may seem more similar to students-all involving nonverbal, numeric material (concerning further deliberations on the differential nature of mathematical and verbal subject areas, see Dweck, 1986). We believe that emotions related to fuzzy domains might therefore also be more heterogeneous - that is, more multidimensional than emotions related to "narrow" (concrete) domains. As such, the subject of German may be both enjoyable and anxiety provoking to a student (e.g., who enjoys poems but is upset by controversy), whereas a student who enjoys mathematics clearly will not be anxious about it (and vice versa). In this way, we would expect to see stronger, more clear-cut within-domain relations for emotions in mathematics classes and less consistent as well as weaker relationships between emotions within the domain of German.
In line with Hypothesis 2c, results of our multilevel approach show that the within-domain interrelations of academic emotions were not significantly different across grade levels. These findings parallel those on the within-domain relations between motivational constructs across diverse achievement contexts, even when mean levels of constructs differed across contexts (Bong, 2001; Gottfried, 1985; Mac Iver, Stipek, \& Daniels, 1991; Meece, Blumenfeld, \& Hoyle, 1988). The results of this study thus indicate that emotional experiences within academic domains do not become increasingly multidimensional after Grade 8. However, longitudinal designs are needed for a more in-depth analysis of this assumption.

\section{Between- and Within-Domain Relations-An Integrative Approach}

In our study, we analyzed both between- and within-domain relations of academic emotions and, in so doing, "turned our data upside down" from one set of analyses to the next. We used scales referring both to a specific emotion and to a specific domain. The resulting set of 20 scales ( 5 emotions $\times 4$ domains) reflects this underlying two-facet design. Results of our multilevel analysis approach clearly show that relations between scales referring to the same emotion but to different domains (analyses of betweendomains relations) were much weaker than relations between scales referring to the same domain but different emotions (analyses of within-domain relations). By implication, it would be more meaningful to group the two-faceted scales into four factors reflecting domain-specific emotionality than to group them into five factors representing domain-general discrete emotions. This result corroborates previous findings showing that emotions are organized in a domain-specific manner (Goetz et al., 2006; Hembree, 1990; Marsh, 1988; Marsh \& Yeung, 1996; Pekrun et al., 2002b) but also goes beyond these findings in showing a greater degree of domain specificity than emotion specificity in students' academic emotions.

\section{Limitations}

In addition to the contributions of the present study for research on the between- and within-domain relations of academic emotions are some limitations that may have implications for future research. Concerning the domains investigated in this study, we analyzed relations for core academic subjects only, similar to Bong's (2001) research on the interrelations between motivational constructs. The domain specificity of emotions experienced in subsidiary school subjects (e.g., in music, sports, and art education) is also a potentially fruitful area for further investigation.

As to the emotions assessed, the present study examined five emotions of critical importance for students' learning and achievement, namely enjoyment, pride, anxiety, anger, and boredom (Pekrun et al., 2002a). By implication, the generalizability of results may be limited to these emotions. Further research on the betweenand within-domain relations of other important academic emotions is warranted (e.g., enthusiasm, relief, relaxation, shame, guilt, or disappointment). Also, we chose to address emotional experiences that are habitually experienced by students in the academic domain. In terms of the trait-state distinction of emotion constructs (Cattell \& Scheier, 1961; Spielberger, 1972), this study thus per- 
tains specifically to students' trait academic emotions (Pekrun et al., 2002a). Future research is warranted concerning the betweenand within-domain relations of students' state emotions-that is, their momentary emotional experiences in given academic situations. Such research could assess discrete state emotional experiences at various points during the school day, for example, through the use of experience-sampling methods (Csikszentmihalyi \& Larson, 1987), making it possible to explore the variability of state emotions across domains.

When interpreting our data, it is also important to take into account that our sample consisted of German students. It is encouraging, however, that the central results of our study are similar to those found by Bong (2001) for between- and within-domain relations of motivational constructs in Korean students. Given the cultural differences between Western European and East Asian countries, this convergence of results implies some degree of generalizability across cultural contexts.

Finally, one limitation of existing research on the domain specificity of academic emotions and motivation, including the present study, concerns the definition of what constitutes a domain. Although academic domains can be defined by their subject matter, students' experiences with these domains are typically contextualized in classroom instruction. As a consequence, students' learning of domain-specific subject matter is intertwined with their participation in a social environment shaped by a specific teacher and group of classmates, both of which can differ across school subjects. By implication, any variation of achievement-related experiences across domains may be due, in part, to a variation in social learning environments across these domains. The present study shares this feature with previous research on the domain specificity of motivational constructs (e.g., Bong, 2001). We encourage future investigations that control for classroom environment factors when analyzing the domain specificity of affective and motivational constructs. This might be possible, for example, in studies conducted in schools where students stay with the same teachers and classmates for each subject, which is the case in many elementary schools. Contrasting findings for such settings with findings for schools in which students switch classes for every subject may serve to disentangle the effects of content domain and classroom context on students' academic emotions.

\section{Implications}

Methodological implications. A combination of structural equation modeling and multilevel analysis proved useful for analyzing between- and within-domain relations of academic emotions. Whereas structural equation modeling allowed us to analyze specific relations among latent factors, multilevel analysis was used to specify indicators for scales within a scale-transcending general factor. Further, the multilevel approach in our study was based on a combined between-person-within-person design (interindividual design at the person level; intraindividual design at the scale and item levels). Because this combination of structural equation modeling and multilevel analyses can provide insights into between- and within-domain relations at different levels of abstraction, this technique may prove useful in further research on the between- and within-domain relations of psychosocial constructs in the classroom. The use of a multilevel approach to derive predictors of the strength of relations by also modeling the slopes (e.g., for effects of subjective beliefs on between-domains relations of emotions) in future projects is also possible.

Assessment of emotions. The present study clearly shows that academic emotions are organized along domain-specific lines, providing empirical support for a domain-specific operationalization of emotions in future research involving such constructs. Consequently, the development of domain-specific instruments for the measurement of students' emotional experiences is encouraged. For the domain of mathematics and for school-age students in Grades 5 to 10, one such instrument is the mathematics version of the Achievement Emotions Questionnaire (Pekrun et al., 2005; assessment of enjoyment, pride, anxiety, anger, boredom, shame, and hopelessness in mathematics). The four-item versions of scales from this instrument, which were used in this study, could be easily adapted for other domains and contexts.

Further, the findings of the present study on within-domain relations indicate that it is reasonable to assess discrete academic emotions instead of more global positive versus negative academic affect. Although some of the relations between discrete emotions were relatively strong at the latent level (e.g., between enjoyment and pride and between anger and boredom), there was sufficient specificity to warrant conceptual and empirical separation, even for closely related emotions. Generally, emotional specificity is supported by differential functions of neighboring discrete emotions, such as anger and boredom or anxiety and hopelessness. Although neighboring emotions may covary because of shared antecedents, they may nevertheless demonstrate considerable specificity in terms of contents and outcomes (Panksepp, 2000; Pekrun, 2006; Pekrun et al., 2004). Also, neighboring emotions showed differences in their degree of domain specificity in the present study. For example, even though enjoyment and pride were closely related, pride showed substantially lower domain specificity than enjoyment at both grade levels, supporting the assumption that discrete emotions can show differential properties despite being significantly correlated.

Implications for educational practice. The findings of the present study have a number of implications for education. With respect to between-domains relations of academic emotions, it appears to be more appropriate for educators to think and speak of domain-specific emotional experiences rather than domain-general experiences (e.g., enjoyment in mathematics rather than schoolrelated enjoyment). Teachers tend to view students' individual characteristics as habitual, domain-general attributes rather than as domain-specific phenomena (Marsh, 1993; Marsh, Smith, \& Barnes, 1983; Pohlmann, Möller, \& Streblow, 2004). The findings of the present study, however, suggest that it may be misleading to make inferences about students' emotions experienced in one domain from their emotions in another domain. Thus, to prevent teachers from making false assumptions with regard to the emotions their students experience in different domains, it is important for teachers to be aware of the domain specificity of students' affective experiences. In addition, our analyses of within-domain relations showed that discrete academic emotions can be empirically distinguished in a given domain, with different emotions showing differential relations with academic achievement. This finding should also encourage educators to avoid thinking about students' emotions in terms of global positive versus negative affect but rather to acknowledge the variety of distinct academic emotions experienced by students as part of the learning process. 


\section{References}

Abu-Hilal, M. M., \& Bahri, T. M. (2000). Self-concept: The generalizability of research on the SDQ, Marsh/Shavelson model and I/E frame of reference model to the United Arab Emirates students. Social Behavior and Personality, 28, 309-322.

Bauer, D. J. (2003). Estimating multilevel linear models as structural equation models. Journal of Educational and Behavioral Statistics, 28(2), 135-167.

Bentler, P. M. (1990). Comparative fit indexes in structural models. Psychological Bulletin, 107, 238-246.

Bollen, K. A. (1989). Structural equations with latent variables. New York: Wiley.

Bong, M. (2001). Between- and within-domain relations of academic motivation among middle and high school students: Self-efficacy, taskvalue and achievement goals. Journal of Educational Psychology, 93, 23-34.

Bong, M., \& Skaalvik, E. M. (2003). Academic self-concept and selfefficacy: How different are they really? Educational Psychology Review, 15(1), 1-40.

Cattell, R. B., \& Scheier, I. H. (1961). The meaning and measurement of neuroticism and anxiety. New York: Ronald Press.

Csikszentmihalyi, M., \& Larson, R. (1987). Validity and reliability of the experience-sampling method. Journal of Nervous and Mental Diseases, 9, 526-536.

Dweck, C. S. (1986). Motivational processes affecting learning. American Psychologist, 41, 1040-1048.

Goetz, T. (2004). Emotionales Erleben und selbstreguliertes Lernen bei Schülern im Fach Mathematik [Students' emotions and self-regulated learning in mathematics]. Munich, Germany: Utz.

Goetz, T., Pekrun, R., Hall, N. C., \& Haag, L. (2006). Academic emotions from a socio-cognitive perspective: Antecedents and domain specificity of students' affect in the context of Latin instruction. British Journal of Educational Psychology, 76, 289-308.

Goetz, T., Zirngibl, A., Pekrun, R., \& Hall, N. C. (2003). Emotions, learning and achievement from an educational-psychological perspective. In P. Mayring \& C. V. Rhoeneck (Eds.), Learning emotions: The influence of affective factors on classroom learning (pp. 9-28). Frankfurt am Main, Germany: Peter Lang.

Gottfried, A. E. (1985). Academic intrinsic motivation in elementary and junior high school students. Journal of Educational Psychology, 77, 631-645.

Hembree, R. (1990). The nature, effects, and relief of mathematics anxiety. Journal for Research in Mathematics Education, 21(1), 33-46.

Hox, J. J. (2002). Multilevel analysis: Techniques and applications. Mahwah, NJ: Erlbaum.

Jöreskog, K., \& Sörbom, D. (2002). LISREL 8.53 [computer software]. Chicago: Scientific Software International.

Kleine, M., Goetz, T., Pekrun, R., \& Hall, N. C. (2005). The structure of students' emotions experienced during an academic achievement test. International Reviews on Mathematical Education, 37, 221-225.

Krapp, A. (2002). Structural and dynamic aspects of interest development: Theoretical considerations from an ontogenetic perspective. Learning and Instruction, 12, 383-409.

Larsen, R. J., \& Diener, E. (1992). Promises and problems with the circumplex model of emotion. In M. S. Clark (Ed.), Review of personality and social psychology: Emotion (Vol. 13, pp. 25-59). Newbury Park, CA: Sage.

Mac Iver, D. J., Stipek, D. J., \& Daniels, D. H. (1991). Explaining within-semester changes in students' effort in junior high school and senior high school courses. Journal of Educational Psychology, 83, 201-211.

Marsh, H. W. (1984). Relations among dimensions of self-attribution, dimensions of self-concept, and academic achievements. Journal of Educational Psychology, 76, 1291-1308.
Marsh, H. W. (1986). Verbal and math self-concept: An internal/external frame of reference model. American Educational Research Journal, 23, 129-149.

Marsh, H. W. (1988). The content specificity of math and English anxieties: The high school and beyond study. Anxiety Research, 1, 137-149.

Marsh, H. W. (1989). Confirmatory factor analyses of multitraitmultimethod data: Many problems and a few solutions. Applied Psychological Measurement, 13, 335-361.

Marsh, H. W. (1993). Academic self-concept: Theory measurement and research. In J. Suls (Ed.), Psychological perspectives on the self (Vol. 4, pp. 59-98). Hillsdale, NJ: Erlbaum.

Marsh, H. W., \& Ayotte, V. (2003). Do multiple dimensions of selfconcept become more differentiated with age? The differential distinctiveness hypothesis. Journal of Educational Psychology, 94, 687-706.

Marsh, H. W., Byrne, B. M., \& Craven, R. (1992). Overcoming problems in confirmatory factor analyses of MTMM data: The correlated uniqueness model and factorial invariance. Multivariate Behavioral Research, 27, 489-507.

Marsh, H. W., Byrne, B. M., \& Yeung, A. S. (1999). Causal ordering of academic self-concept and achievement: Reanalysis of a pioneering study and revised recommendations. Educational Psychologist, 34, 155167.

Marsh, H. W., Hau, K.-T., \& Wen, Z. (2004). In search of golden rules: Comment on hypothesis-testing approaches to setting cutoff values for fit indexes and dangers in overgeneralizing $\mathrm{Hu}$ and Bentler's (1999) findings. Structural Equation Modeling, 11, 320-341.

Marsh, H. W., Smith, I. A., \& Barnes, J. (1983). Multitrait and multimethod analysis of the Self-Description Questionnaires: Student-teacher agreement on multidimensional ratings of student self-concept. American Educational Research Journal, 20, 333-357.

Marsh, H. W., \& Yeung, A. S. (1996). The distinctiveness of affects in specific school subjects: An application of confirmatory factor analysis with the National Educational Longitudinal Study of 1988. American Educational Research Journal, 33, 665-689.

Meece, J. L., Blumenfeld, P. C., \& Hoyle, R. H. (1988). Students' goal orientations and cognitive engagement in classroom activities. Journal of Educational Psychology, 80, 514-523.

Mehta, P. D., \& Neale, M. C. (2005). People are variables too: Multilevel structural equations modeling. Psychological Methods, 10, 259-284.

Möller, J., \& Köller, O. (2001). Dimensional comparisons: An experimental approach to the internal/external frame of reference model. Journal of Educational Psychology, 93, 826-835.

Muthén, L. K., \& Muthén, B. O. (2006). Mplus user's guide (4th ed.). Los Angeles: Muthén \& Muthén.

National Center for Educational Statistics (1986). High School and Beyond, 1980: Sophomore cohort second follow-up (1984). Data file user's manual. Ann Arbor, MI: Inter-university Consortium for Political and Social Research.

Panksepp, J. (2000). Emotions as natural kinds within the mammalian brain. In M. Lewis \& J. Haviland-Jones (Eds.), Handbook of emotions (pp. 137-156). New York: Guilford Press.

Pekrun, R. (1992). The impact of emotions on learning and achievement: Towards a theory of cognitive/motivational mediators. Applied Psychology: An International Review, 41, 359-376.

Pekrun, R. (2000). A social-cognitive, control-value theory of achievement emotions. In J. Heckhausen (Ed.), Motivational psychology of human development (pp. 143-163). Oxford, England: Elsevier.

Pekrun, R. (2006). The control-value theory of achievement emotions: Assumptions, corollaries, and implications for educational research and practice. Educational Psychology Review, 18, 315-341.

Pekrun, R., Elliot, A. J., \& Maier, M. A. (2006). Achievement goals and discrete achievement emotions: A theoretical model and prospective test. Journal of Educational Psychology, 98, 583-597.

Pekrun, R., Goetz, T., \& Frenzel, A. C. (2005). Achievement Emotions 
Questionnaire-Mathematics (AEQ-M) user's manual. Munich, Germany: Department of Psychology, University of Munich.

Pekrun, R., Goetz, T., Perry, R., Kramer, K., Hochstadt, M., \& Molfenter, S. (2004). Beyond test anxiety: Development and validation of the Test Emotions Questionnaire (TEQ). Anxiety, Stress, and Coping, 17, 287316

Pekrun, R., Goetz, T., Titz, W., \& Perry, R. (2002a). Academic emotions in students' self-regulated learning and achievement: A program of qualitative and quantitative research. Educational Psychologist, 37(2), 91-105.

Pekrun, R., Goetz, T., Titz, W., \& Perry, R. P. (2002b, April). A social cognitive, control-value theory of achievement emotions: Social antecedents and achievement effects of students' domain-related emotions. Paper presented at the meeting of the American Educational Research Association, New Orleans, LA.

Pohlmann, B., Möller, J., \& Streblow, L. (2004). Zur Fremdeinschätzung von Schülerselbstkonzepten durch Lehrer und Mitschüler [On students' self-concepts inferred by teachers and classmates]. German Journal of Educational Psychology, 18, 157-169.

Raudenbush, S. W., \& Bryk, A. S. (2002). Hierarchical linear models: Applications and data analysis methods (2nd ed.). Thousand Oaks, CA: Sage.

Ricci-Bitti, P., \& Scherer, K. R. (1986). Interrelations between antecedents, reactions, and coping responses. In K. R. Scherer, H. G. Wallbott, \& A. B. Summerfield (Eds.), Experiencing emotion: A cross-cultural study (pp. 129-141). Cambridge, England: Cambridge University Press.

Richardson, F. C., \& Suinn, R. M. (1972). The Mathematics Anxiety Rating Scale: Psychometric data. Journal of Counseling Psychology, 19, $551-554$.

Roseman, I. J. (2001). A model of appraisal in the emotion system: Integrating theory, research, and applications. In K. R. Scherer, A. Schorr, \& T. Johnstone (Eds.), Appraisal processes in emotion (pp. 68 -91). Oxford, England: Oxford University Press.

Roseman, I. J., Antoniou, A. A., \& Jose, P. E. (1996). Appraisal determinants of emotions: Constructing a more accurate and comprehensive theory. Cognition and Emotion, 10, 241-277.
Roseman, I. J., \& Smith, C. A. (2001). Appraisal theory: Overview, assumptions, varieties, controversies. In K. R. Scherer, A. Schorr, \& T. Johnstone (Eds.), Appraisal processes in emotion (pp. 3-19). Oxford, England: Oxford University Press.

Scherer, K. R. (2001). Appraisal considered as a process of multilevel sequential checking. In K. R. Scherer, A. Schorr, \& T. Johnstone (Eds.), Appraisal processes in emotion (pp. 92-120). Oxford, England: Oxford University Press.

Shavelson, R. J., Hubner, J. J., \& Stanton, G. C. (1976). Self-concept: Validation of construct interpretations. Review of Educational Research, 46, 407-441.

Shaver, P., Schwartz, J., Kirson, D., \& O'Connor, C. (1987). Emotion knowledge: Further exploration of a prototype approach. Journal of Personality and Social Psychology, 52, 1061-1086.

Spielberger, C. D. (1972). Anxiety as an emotional state. In C. D. Spielberger (Ed.), Anxiety: Current trends in theory and research (Vol. 1, pp. 23-49). New York: Academic Press.

Steiger, J. H., \& Lind, J. C. (1980, June). Statistically based tests for the number of common factors. Paper presented at the meeting of the Psychometric Society, Iowa City, IA.

Stevenson, H. W., \& Newman, R. S. (1986). Long-term prediction of achievement and attitudes in mathematics and reading. Child Development, 57, 646-659.

Tucker, L. R., \& Lewis, C. (1973). A reliability coefficient for maximum likelihood factor analysis. Psychometrika, 38, 1-10.

Wallbott, H. G., \& Scherer, K. R. (1988). How universal and specific is emotional experience? Evidence from 27 countries on five continents. In K. R. Scherer (Ed.), Facets of emotion: Recent research (pp. 31-56). Hillsdale, NJ: Erlbaum.

Watson, D., \& Tellegen, A. (1985). Toward a consensual structure of mood. Psychological Bulletin, 98, 219-235.

Weiner, B. (1985). An attributional theory of achievement motivation and emotion. Psychological Review, 92, 548-573.

Zeidner, M. (1998). Test anxiety: The state of the art. New York: Plenum Press. 
Appendix A

Descriptive Statistics of Academic Emotion Scales and Achievement Scores

\begin{tabular}{|c|c|c|c|c|c|c|}
\hline \multirow[b]{2}{*}{ Scale } & \multicolumn{3}{|c|}{ Grade $8(n=307)$} & \multicolumn{3}{|c|}{ Grade $11(n=235)$} \\
\hline & $M$ & $S D$ & $\alpha$ & $M$ & $S D$ & $\alpha$ \\
\hline \multicolumn{7}{|l|}{ Enjoyment } \\
\hline Mathematics & 2.74 & 1.16 & .92 & 2.45 & 1.15 & .93 \\
\hline Physics & 2.81 & 1.06 & .90 & 2.44 & 1.08 & .93 \\
\hline German & 2.78 & 0.96 & .86 & 2.76 & 0.94 & .87 \\
\hline English & 3.24 & 0.97 & .87 & 2.98 & 1.11 & .93 \\
\hline \multicolumn{7}{|l|}{ Pride } \\
\hline Mathematics & 2.92 & 1.20 & .93 & 2.60 & 1.13 & .91 \\
\hline Physics & 2.83 & 1.10 & .92 & 2.66 & 1.05 & .91 \\
\hline German & 2.88 & 0.88 & .78 & 2.84 & 0.93 & .84 \\
\hline English & 3.25 & 0.93 & .86 & 3.02 & 1.05 & .91 \\
\hline \multicolumn{7}{|l|}{ Anxiety } \\
\hline Mathematics & 2.15 & 1.10 & .90 & 2.46 & 1.11 & .87 \\
\hline Physics & 1.96 & 1.03 & .89 & 2.10 & 0.96 & .86 \\
\hline German & 1.45 & 0.58 & .72 & 1.38 & 0.49 & .67 \\
\hline English & 1.61 & 0.71 & .82 & 1.67 & 0.84 & .87 \\
\hline \multicolumn{7}{|l|}{ Anger } \\
\hline Mathematics & 2.30 & 1.08 & .86 & 2.70 & 1.09 & .84 \\
\hline Physics & 2.10 & 1.06 & .87 & 2.44 & 0.99 & .82 \\
\hline German & 1.92 & 0.81 & .73 & 1.97 & 0.71 & .66 \\
\hline English & 1.81 & 0.76 & .75 & 1.93 & 0.87 & .79 \\
\hline \multicolumn{7}{|l|}{ Boredom } \\
\hline Mathematics & 2.38 & 1.11 & .88 & 2.58 & 1.11 & .91 \\
\hline Physics & 2.22 & 1.11 & .91 & 2.72 & 1.10 & .90 \\
\hline German & 2.56 & 1.08 & .88 & 2.86 & 1.05 & .90 \\
\hline English & 2.03 & 0.94 & .90 & 2.36 & 1.04 & .91 \\
\hline \multicolumn{7}{|l|}{ Achievement } \\
\hline Mathematics & 3.69 & 1.00 & & 3.60 & 1.10 & \\
\hline Physics & 3.87 & 0.92 & & 3.87 & 1.01 & \\
\hline German & 3.97 & 0.70 & & 4.17 & 0.75 & \\
\hline English & 3.90 & 0.93 & & 4.03 & 0.90 & \\
\hline
\end{tabular}

Note. For the emotion scales, means and standard deviations refer to sum scales, which were divided by number of scale items. Four items were used for each scale; the response format consisted of a 5-point Likert scale ranging from (1) strongly disagree to (5) strongly agree. For achievement, grades are depicted; in the German school system, grades vary between 1 (very good) and 6 (insufficient). These grade measures were inverted. Thus, high values on the inverted grades variable represent good achievement outcomes. 


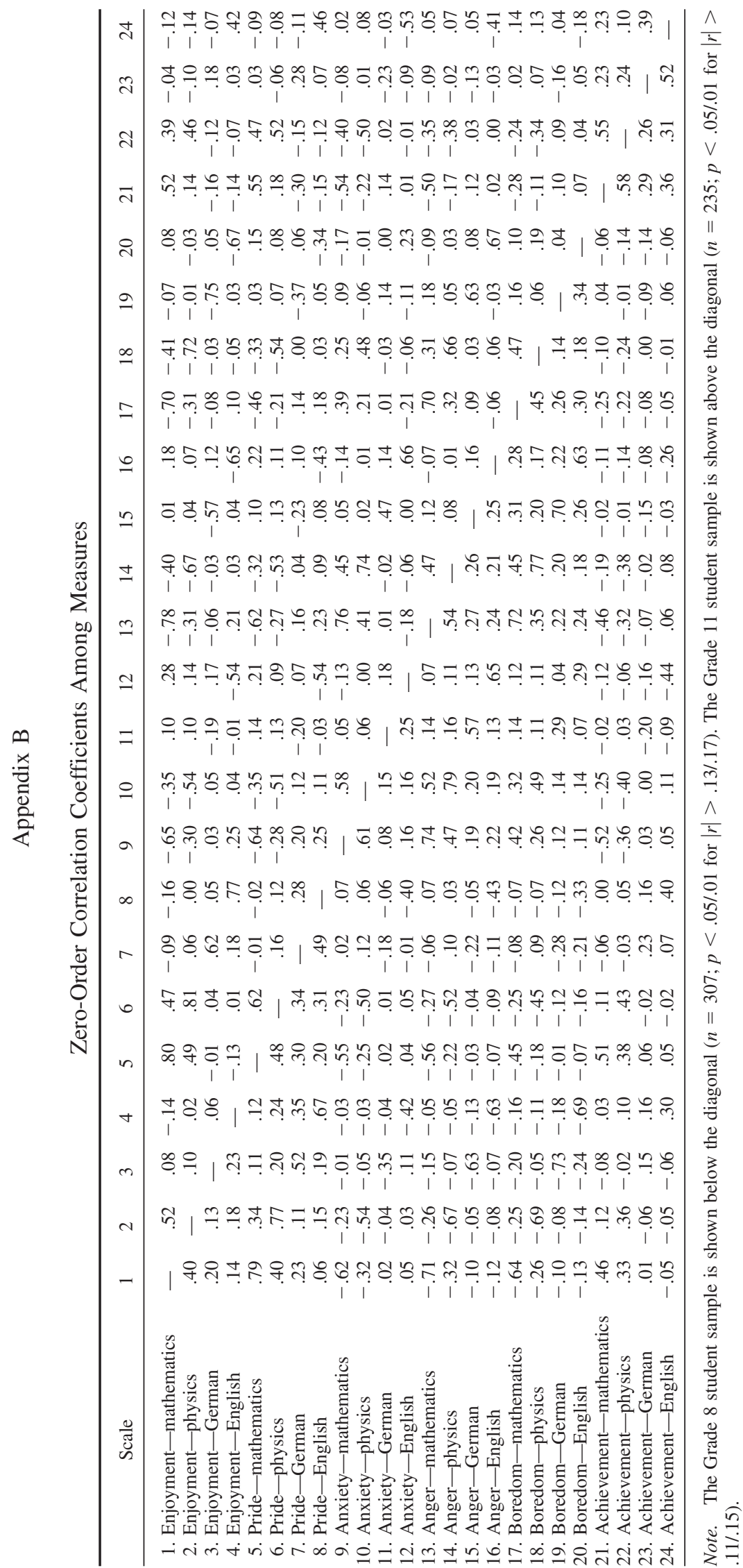




\section{Appendix C}

\section{Homogeneity Index Comparison Procedure}

To test for significant differences between the homogeneity indexes for the two grade levels, we specified a two-group (eighth and eleventh grades), three-level model in Mplus for each emotion (i.e., between-domains relations; grade-level differences in $h(\mathrm{~d})$; see Table 3) as well as for each domain (i.e., within-domain relations; grade-level differences in $h(\mathrm{e})$; see Table 6). As it is only possible to calculate two-level models in Mplus, we specified the first level as a constrained confirmatory factor analysis (see Bauer, 2003; Mehta \& Neale, 2005). Concerning grade-level differences in achievement scores (i.e., between-domains relations; gradelevel differences in $h(\mathrm{~d})$; see Table 3), we specified a two-level model in Mplus. By setting nonlinear constraints that could be specified in Mplus, we could run pairwise tests to determine whether the difference of the homogeneity indexes between the two grade levels was statistically significantly different from zero.
The pairwise differences in the homogeneity indexes between the emotions within the grade levels (i.e., between-domains relations; see Table 3) as well as differences in the homogeneity indexes between the domains within the grade levels (i.e., within-domain relations; see Table 6) were tested via a similar procedure. Again, a three-level model with the first level as a constrained confirmatory factor analysis was specified for each pair of emotions within the two grade levels. By setting nonlinear constraints, we were able to test whether the difference between the homogeneity indexes for the two emotions was statistically significantly different from zero. 